\title{
Dinitrosulfodienes of the 2,5-dihydrothiophene-1,1-dioxide series in reactions with nucleophiles
}

\author{
Valentina M. Berestovitskaya and Irina E. Efremova \\ Herzen Russian State Pedagogical University, \\ 191186 Russia, St Petersburg, Moika 48 \\ E-mail:kohrgpu@yandex.ru, eie2000@mail.ru
}

\section{Dedicated to Academician Boris Alexandrovich Trofimov}

(received 01 June 03; accepted 07 July 03; published on the web 17 July 03)

\begin{abstract}
Reactions of dinitrosulfo-dienes of the dihydrothiophene- 1,1 dioxide series, 3-methyl-4-nitro-2(1'-nitro-1'-aryl)methylene-2,5-dihydrothiophene- 1,1-dioxides, with $\mathrm{N}$ - and S- nucleophiles are presented. Interaction between N,N-dimethylaniline and aromatic thiols leads to the electrontransfer products. In the first case, stable molecular charge-transfer complexes are formed, while the S -nucleophiles lead to diaryl disulfides and products of reduction of the initial compounds. The reaction with the barely oxidizing sodium azide proceeds according to the second competitive route and results in the formation of products of nucleophilic vinylic substitution. Both pathways appear to be possible in the interaction with dodecanethiol, while the major process is $\mathrm{S}_{\mathrm{N}} \mathrm{Vin}$.
\end{abstract}

Keywords: Heterocycles, 2,5-dihydrothiophene- 1,1-dioxides, 1,4-dinitro-1,3-dienes, nucleophiles, electron transfer

\section{Introduction}

Conjugated 1,4-dinitro-1,3-dienes can undergo competitive electron transfer reactions, nucleophilic addition and vinyl substitution ${ }^{1}$ and are convenient substrates for studying the chemo- and regioorientation of chemical processes.

Heterocyclic dinitrosulfo dienes of the dihydrothiophene- 1,1-dioxide series [3-methyl-4-nitro2-(1'-nitro-1'-aryl)methylene-2,5-dihydrothiophene- 1,1-dioxides] 1, 2, which we have synthesized previously, ${ }^{2,3}$ differ substantially from the symmetrical models with the open chain; they are characterized by a fixed s-trans- conformation, asymmetry in the position of the substituents at the double bonds, the presence of the additional electron acceptor function $\left(\mathrm{SO}_{2}\right.$ group) and steric hindrance of the molecules ${ }^{3}$ (Fig. 1). We have studied the ways in which these unusual dinitrodiene structures $\mathbf{1 , 2}$ react with nucleophiles. 


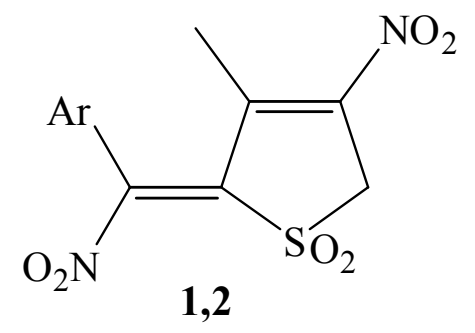

$\mathrm{Ar}=\mathrm{C}_{6} \mathrm{H}_{5}(\mathbf{1}), p-\mathrm{ClC}_{6} \mathrm{H}_{4}(\mathbf{2})$

\section{Figure 1}

\section{Results and Discussion}

To reveal the factors influencing the chemo- and regio- orientation of the reactions of the $Z, E$ dinitrosulfo dienes $\mathbf{1}$ and $\mathbf{2}$ we have investigated their interaction with N- and S- nucleophiles, which are characterized by different ionization potentials. Compounds $\mathbf{1}, \mathbf{2}$ underwent transformations along two competitive pathways-electron transfer, and nucleophilic vinyl substitution. The exact pathway depends on the reducing properties of the reagent.

The oxidizing properties of the dinitrosulfo dienes 1, 2 were exhibited most intensively in the action of substances with low ionization potential. In this case, the electron-transfer process can stop upon formation of the charge transfer complex, or proceed further, resulting in dinitronates or products of their transformations. Thus, reactions of compounds $\mathbf{1}, \mathbf{2}$ with N,N-dimethylaniline led to stable crystalline molecular complexes 3, 4, in which the electron-deficient structure of the heterocyclic dinitrosulfo diene acts as an acceptor (Scheme 1). The presence of a charge-transfer band at $\lambda_{\max } 450 \mathrm{~nm}(\varepsilon 2000-4000)$ in the electron spectra of compounds $\mathbf{3}, \mathbf{4}$ indicates the complex nature of these substances; their binary composition is confirmed by ${ }^{1} \mathrm{H}$ NMR spectra and elemental analytical data. The ability of the dinitrosulfo dienes $\mathbf{1 ,} \mathbf{2}$ to form stable complexes, which is not typical for their linear analogs, is determined by the geometry of the 2,5dihydrothiophene- dioxide ring, which is close to planar. ${ }^{3}$ This is important for the formation of molecular complexes. ${ }^{4,5}$ It is worth mentioning that complexes of 2,4-dinitrothiophene- 1,1dioxides with pyridine are the closest in their structure to the adducts $\mathbf{3}, \mathbf{4}$. ${ }^{6,7}$

On interaction of compound $\mathbf{1}$ with easily oxidizing S-nucleophiles such as aromatic thiols $\left(\mathrm{C}_{6} \mathrm{H}_{5} \mathrm{SH}, p-\mathrm{ClC}_{6} \mathrm{H}_{4} \mathrm{SH}\right)$, electron-transfer processes proceed in a different manner. In this case, the arene-thiol is oxidized into the corresponding diaryl disulfide [diphenyl disulfide, di- $(p-$ chlorophenyl) disulfide], while the dinitrosulfo diene 1 led to the known 2-benzylidene-3-methyl-4nitro-2,5-dihydrothiophene-1,1-dioxide $\mathbf{5}^{8}$ (Scheme 1).

The higher ionization potential of alkanethiols ${ }^{9}$ decreases the probability of oxidation-reduction processes. Thus, the interaction between 1, 2 and dodecanethiol gave the disulfide $\mathrm{C}_{12} \mathrm{H}_{25} \mathrm{~S}_{-} \mathrm{SC}_{12} \mathrm{H}_{25}$ and compound $\mathbf{5}$, in yields not exceeding 7\%, the major products of the reaction being the isomeric alkylthionitrosulfo-dienes: 4-dodecylthio-3-methyl-2-(1'-nitro-1'-aryl)methylene-2,5-dihydrothiophene-1,1dioxides 6, 7, and the 2-(1'-dodecylthio-1'-aryl)methylene-3-methyl-4-nitro-2,5-dihydrothiophene- 1,1- 
dioxides 8, 9 (Scheme 2). The formation of these dienes is a result of two competing processes: nucleophilic vinyl substitution at the endocyclic nitrovinyl fragment and nucleophilic vinyl substitution at the exocyclic nitrovinyl fragment.

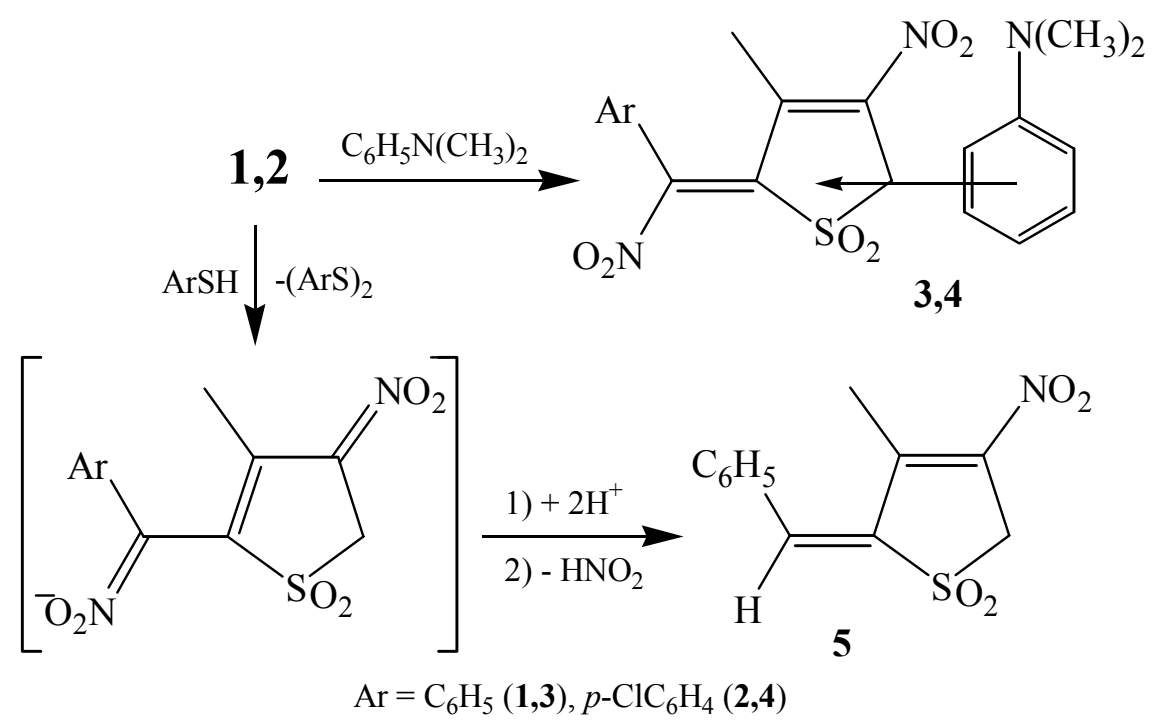

\section{Scheme 1}

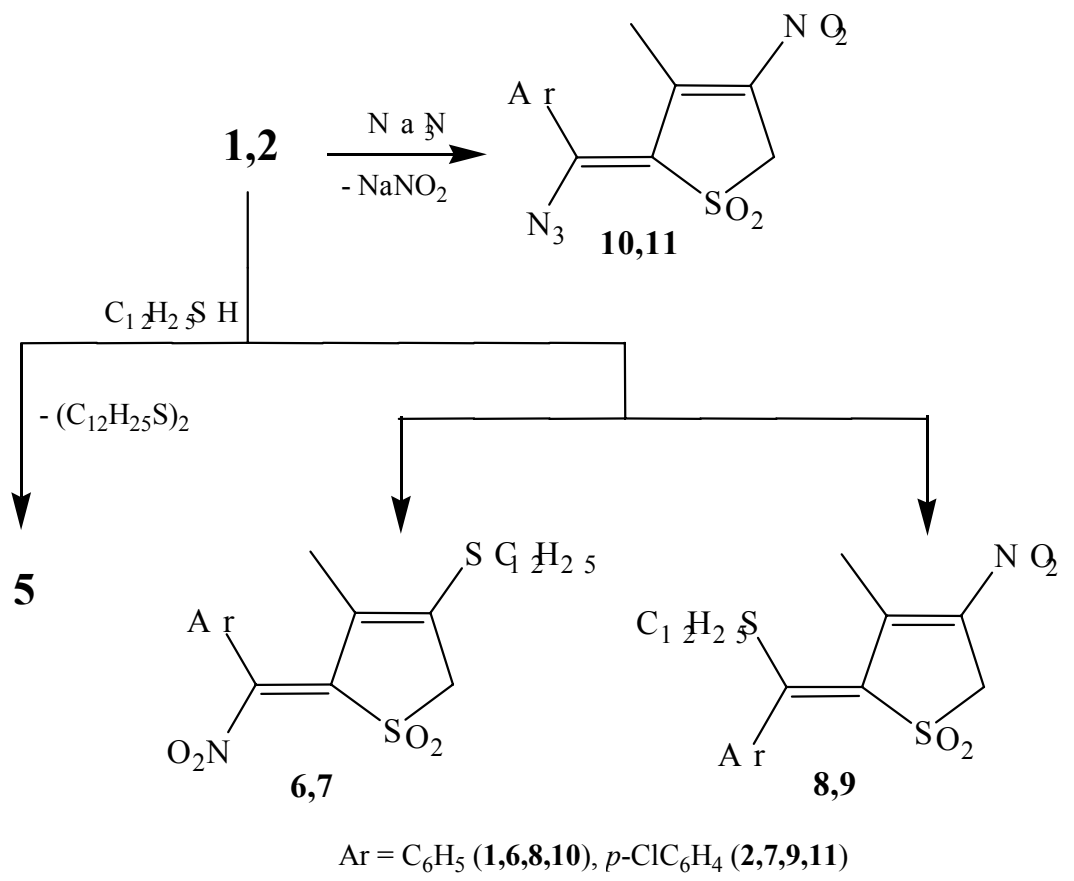

\section{Scheme 2}

The reactions of the dinitrosulfo dienes $\mathbf{1 , 2}$ with the barely oxidizing sodium azide proceed predominantly in accordance with the $\mathrm{S}_{\mathrm{N}}$ Vin mechanism and result in formation of products of 
substitution at the exocyclic nitrovinyl fragment, 2-(1'-azido-1'-aryl)methylene-3-methyl-4-nitro2,5-dihydrothiophene- 1,1-dioxides 10, 11 (Scheme 2).

The structures of the original alkylthio- and azido- derivatives 6-11 and their configuration are determined by comparative analysis of their ${ }^{1} \mathrm{H}$ NMR spectra and the characteristics similar to the starting dinitrosulfo dienes $\mathbf{1}, \mathbf{2}^{3}$. The main objective was the chemical shift value of the methyl group of the heterocycle, which is very sensitive to the chemical environment. The close values of these data in the spectra of compounds 10,11 (2.00 ppm) and the starting $Z, E$-dinitrosulfo dienes 1, $2(1.95 \mathrm{ppm})$ testify to the unchanged locations of the nitro-, methyl-, and phenyl groups, that are possible only in the case of substitution of the exocyclic nitro group and conservation of the $Z, E$ configuration in the products. In the $E, E$-isomers of compounds $\mathbf{8 , 9}$, as well as in the starting $E, E$ dinitrosulfo dienes, the protons of the $\mathrm{CH}_{3}$ group resonate at lower field, 2.50-2.90 ppm, owing to the absence of the anisotropic shielding effect of the benzene ring. ${ }^{3}$ The essential shift of the methyl groups' protons' signals in compounds 6, 7 towards high field (1.75 ppm) proves the cis- location of the nitro- and alkylthio- groups, and hence substitution of the endocyclic nitro group in these compounds.

\section{Conclusions}

Reactions of the dinitrosulfo dienes of a series of 2,5-dihydrothiophene- 1,1-dioxides with some $\mathrm{N}$ - and S-nucleophiles have been studied. It has been shown that the heterocyclic 1,4-dinitro-1,3dienes react with nucleophiles along two competitive pathways: electron transfer and $\mathrm{S}_{\mathrm{N}}$ Vin processes, whose ratio depends on the reducing properties of the reagents. In contrast to linear objects, the rigid dinitrosulfo dienes of the dihydrothiophene-1,1-dioxide series have a tendency to form stable molecular complexes in electron-transfer reactions.

\section{Experimental Section}

General Procedures. IR spectra were recorded on a Specord IR-75 spectrophotometer. ${ }^{1} \mathrm{H}$ NMR spectra were obtained on a Bruker AC-200 spectrometer at $200 \mathrm{MHz}$ in $\mathrm{CDCl}_{3}$ with $\mathrm{HMDS}$ as an internal standard. UV spectra were recorded on a SF-46 instrument. Column chromatography was carried out on silica L $100 / 250 \mu$.

The starting dinitrosulfo dienes, 3-methyl-4-nitro-2-(1'-nitro-1'-aryl)methylene-2,5-dihydrothiophene-1,1-dioxides) 1, 2, were prepared according to ref. 3 .

General procedure for molecular complexes of 3-methyl-4-nitro-2-(1'-nitro-1'-aryl)methylene2,5-dihydrothiophene-1,1- dioxides with $N, N$-dimethylaniline $(3,4)$ 
$N, N$-dimethylaniline $(2.8 \mathrm{mmol})$ was added dropwise to $\mathbf{1}$, or $2(0.9 \mathrm{mmol})$ in ethanol $(10 \mathrm{~mL})$. The reaction mixture was stirred for $2 \mathrm{~h}$, the precipitated $\mathbf{3}$, or $\mathbf{4}$ was filtered off, washed with ethanol and ether, and dried in air.

Molecular complex (3). 29\%; mp 299-300 ${ }^{\circ}$; ${ }^{1} \mathrm{H}$ NMR $\delta\left(\mathrm{CDCl}_{3}\right) 1.90\left(3 \mathrm{H}, \mathrm{s}, \mathrm{CH}_{3}\right), 3.00(6 \mathrm{H}, \mathrm{s}$, $\left.\mathrm{CH}_{3}\right), 4.50\left(2 \mathrm{H}, \mathrm{s}, \mathrm{CH}_{2}\right), 6.60,6.80,7.40,7.55,7.68,7.75,(10 \mathrm{H}, \mathrm{m}, \mathrm{Ar}-\mathrm{H})$; UV $\left(\mathrm{CH}_{3} \mathrm{CN}\right)(\varepsilon) 270$ (11600), 340 (6100), 450 (2000), 650 (500) nm; Anal. Calcd. for $\mathrm{C}_{20} \mathrm{H}_{21} \mathrm{~N}_{3} \mathrm{O}_{6} \mathrm{~S}$ : C 55.68, H 4.87, N 9.74; found C 55.58, 55.57, H 4.74, 4.78, N 9.92, 9.66\%.

Molecular complex (4). 27\%; mp 297-299 ${ }^{\circ} ;{ }^{1} \mathrm{H}$ NMR $\delta\left(\mathrm{CDCl}_{3}\right) 1.95\left(3 \mathrm{H}, \mathrm{s}, \mathrm{CH}_{3}\right) ; 3.00(6 \mathrm{H}, \mathrm{s}$, $\left.\mathrm{CH}_{3}\right) ; 4.55\left(2 \mathrm{H}, \mathrm{s}, \mathrm{CH}_{2}\right) ; 6,65,6.80,7.45,7.50,7.70,7.80,(9 \mathrm{H}, \mathrm{m}, \mathrm{Ar}-\mathrm{H}$.$) ; UV \left(\mathrm{CH}_{3} \mathrm{CN}\right)(\varepsilon) 265$ (16500), 340 (13300), 450 (3900), 710 (400) nm; Anal. Calcd. for $\mathrm{C}_{20} \mathrm{H}_{20} \mathrm{ClN}_{3} \mathrm{O}_{6} \mathrm{~S}: \mathrm{N}$ 9.02; found N 9.00, 9.02\%.

Reactions of 3-methyl-4-nitro-2-(1'-nitro-1'-aryl)methylene-2,5-dihydrothiophene- 1,1dioxides (1) with thiophenol or $p$-chloro-thiophenol

General procedure. Thiophenol $(1.45 \mathrm{mmol})$ was added to a suspension of $1(0.97 \mathrm{mmol})$ in methanol $(10 \mathrm{~mL})$, then the mixture was stirred at room temperature. After $30 \mathrm{~min}$, the resulting solution was concentrated, and the precipitated diphenyl disulfide was filtered off. The filtrate was concentrated to give 2-benzylidene-2,5-dihydro-3-methyl-4-nitrothiophene-1,1-dioxide, 5, which was purified by silica chromatography, eluting with hexane. A mixture of $\mathbf{5}$ and a sample prepared according to ref. 8, gave no depression of $\mathrm{mp}$; in this way 5 was identified.

Diphenyl disulfide. $96 \%$; mp 58-60 $\mathrm{C}$ (from benzene) (lit. ${ }^{10} \mathrm{mp} 61{ }^{\circ} \mathrm{C}$ ); ${ }^{1} \mathrm{H} \mathrm{NMR} \delta\left(\mathrm{CDCl}_{3}\right) 7.22-$ 7.65 (10H, m, 2xPh); Anal. Calcd. for $\mathrm{C}_{12} \mathrm{H}_{10} \mathrm{~S}_{2}$ : C 66.06, H 4.59, found $\mathrm{C} 66.11,66.10$, H 5.00, $4.98 \%$.

Di-(p-chlorophenyl) disulfide. $91 \%$; mp $71-72{ }^{\circ} \mathrm{C}$ (from benzene) $\left(\right.$ lit. $\left.{ }^{11} \mathrm{mp} 73-74{ }^{\circ} \mathrm{C}\right) ;{ }^{1} \mathrm{H}$ NMR $\delta$ $\left(\mathrm{CDCl}_{3}\right) 7.30(4 \mathrm{H}, \mathrm{d}, \mathrm{J}=8.5 \mathrm{~Hz}, \mathrm{Ar}), 7.85(4 \mathrm{H}, \mathrm{d}, \mathrm{J}=8.5 \mathrm{~Hz}, \mathrm{Ar})$; Anal. Calcd. for $\mathrm{C}_{12} \mathrm{H}_{8} \mathrm{Cl}_{2} \mathrm{~S}_{2}: \mathrm{C}$ 50.17, H 2.78; found C 50.20, 50.19, H 3.00, 2.98\%.

General procedure for reactions of 3-methyl-4-nitro-2-(1'-nitro-1'-aryl)methylene-2,5dihydrothiophene- 1,1-dioxides $(1,2)$ with dodecanethiol. Synthesis of 4-dodecylthio-3methyl-2-(1'-nitro-1'-phenyl)methylene-2,5-dihydrothiophene- 1,1-dioxide (6), 4-dodecylthio3-methyl-2-(1'-nitro-1'-p-chlorophenyl)methylene-2,5-dihydrothiophene- 1,1-dioxide (7), 2(1'-dodecylthio-1'-phenyl)methylene-3-methyl-4-nitro-2,5-dihydrothiophene- 1,1-dioxide (8), 2-(1'-dodecylthio-1'-p-chlorophenyl)methylene-3-methyl-4-nitro-2,5-dihydrothiophene- 1,1dioxide (9)

Dodecanethiol $(4.6 \mathrm{mmol})$ was added to a suspension of 1 or $2(0.97 \mathrm{mmol})$ in dry methanol $(15 \mathrm{~mL})$. The reaction mixture was stirred for 6 days then concentrated and purified by chromatography on silica. Petroleum eluted didodecyl disulfide (5-7\%), mp 34-35 ${ }^{\circ} \mathrm{C}$ (from hexane) (lit. ${ }^{12} \mathrm{mp} 34.5-35^{\circ} \mathrm{C}$ ). Hexane as eluent gave 5. A mixture of 5 and a sample, prepared according to ref. 8 , gave no depression of $\mathrm{mp}$; in this way $\mathbf{5}$ was identified. Benzene eluted mixtures of isomers $\mathbf{6}$, and $\mathbf{8}$, or $\mathbf{7}$, and $\mathbf{9}$, correspondingly. 
4-Dodecylthio-3-methyl-2-(1'-nitro-1'-phenyl)methylene-2,5-dihydrothiophene- 1,1-dioxide (6), and 2-(1'-dodecylthio-1'-phenyl)methylene-3-methyl-4-nitro-2,5-dihydrothiophene- 1,1dioxide (8). (identified as a mixture in $3: 1$ ratio): $\mathrm{R}_{\mathrm{f}} 0.56,0.54$ (hexane-acetone, 3:1); total yield $34 \% ;{ }^{1} \mathrm{H}$ NMR $\delta\left(\mathrm{CDCl}_{3}\right)$ for 6, 0.90-1,30 $\left(23 \mathrm{H}, \mathrm{m}, \mathrm{C}_{11} \mathrm{H}_{23}\right), 1.75\left(3 \mathrm{H}, \mathrm{s}, \mathrm{CH}_{3}\right), 2.50(2 \mathrm{H}, \mathrm{t}, \mathrm{J}=7.0$ $\left.\mathrm{Hz}, \mathrm{CH}_{2} \mathrm{~S}\right), 4.40\left(2 \mathrm{H}, \mathrm{s}, \mathrm{CH}_{2}\right), 7.40(2 \mathrm{H}, \mathrm{d}, \mathrm{J}=8.5 \mathrm{~Hz}, \mathrm{Ph}), 7.56(3 \mathrm{H}, \mathrm{d}, \mathrm{J}=8.5 \mathrm{~Hz}, \mathrm{Ph})$; for 8, 0.90-1,30 (23H, m, $\left.\mathrm{C}_{11} \mathrm{H}_{23}\right), 2.50\left(2 \mathrm{H}, \mathrm{t}, \mathrm{J}=7.0 \mathrm{~Hz}, \mathrm{CH}_{2} \mathrm{~S}\right), 2.90\left(3 \mathrm{H}, \mathrm{s}, \mathrm{CH}_{3}\right), 4.20\left(2 \mathrm{H}, \mathrm{s}, \mathrm{CH}_{2}\right)$, $7.40(2 \mathrm{H}, \mathrm{d}, \mathrm{J}=8.5 \mathrm{~Hz}, \mathrm{Ph}), 7.56(3 \mathrm{H}, \mathrm{d}, \mathrm{J}=8.5 \mathrm{~Hz}, \mathrm{Ph}) ; \mathrm{IR} \vee\left(\mathrm{CHCl}_{3}\right) 1590(\mathrm{C}=\mathrm{C}), 1530,1320$ $\left(\mathrm{NO}_{2}\right), 1320,1130\left(\mathrm{SO}_{2}\right) \mathrm{cm}^{-1}$; Anal. Calcd. for $\mathrm{C}_{24} \mathrm{H}_{35} \mathrm{NO}_{4} \mathrm{~S}: \mathrm{N} 3.01$; found N 3.27, 3.29\%.

4-Dodecylthio-3-methyl-2-(1'-nitro-1'-p-chlorophenyl)methylene-2,5-dihydrothiophene- 1,1dioxide (7), 2-(1'-dodecylthio-1'-p-chlorophenyl)methylene-3-methyl-4-nitro-2,5-dihydrothiophene1,1 dioxide (9). (identified in a mixture in 3:1 ratio): $\mathrm{R}_{\mathrm{f}}$ 0.58, 0.56 (hexane-acetone, 3:1); total yield 28\%; ${ }^{1} \mathrm{H}$ NMR $\delta\left(\mathrm{CDCl}_{3}\right)$ for 7: 0.90-1,30 $\left(23 \mathrm{H}, \mathrm{m}, \mathrm{C}_{11} \mathrm{H}_{23}\right), 1.75\left(3 \mathrm{H}, \mathrm{s}, \mathrm{CH}_{3}\right), 2.50(2 \mathrm{H}, \mathrm{t}, \mathrm{J}=7.0$ $\left.\mathrm{Hz}, \mathrm{CH}_{2} \mathrm{~S}\right), 4.40\left(2 \mathrm{H}, \mathrm{s}, \mathrm{CH}_{2}\right), 7.35(2 \mathrm{H}, \mathrm{d}, \mathrm{J}=9.0 \mathrm{~Hz}, \mathrm{Ar}), 7.55(2 \mathrm{H}, \mathrm{d}, \mathrm{J}=9.0 \mathrm{~Hz}, \mathrm{Ar})$. For 9: 0.90-1,30 (23H, m, $\left.\mathrm{C}_{11} \mathrm{H}_{23}\right), 2.50\left(2 \mathrm{H}, \mathrm{t}, \mathrm{J}=7.0 \mathrm{~Hz}, \mathrm{CH}_{2} \mathrm{~S}\right), 2.80\left(3 \mathrm{H}, \mathrm{s}, \mathrm{CH}_{3}\right), 4.25\left(2 \mathrm{H}, \mathrm{s}, \mathrm{CH}_{2}\right)$, $7.35(2 \mathrm{H}, \mathrm{d}, \mathrm{J}=9.0 \mathrm{~Hz}, \mathrm{Ar}), 7.55(2 \mathrm{H}, \mathrm{d}, \mathrm{J}=9.0 \mathrm{~Hz}, \mathrm{Ar})$; IR $v\left(\mathrm{CHCl}_{3}\right) 1590(\mathrm{C}=\mathrm{C}), 1520,1320$ $\left(\mathrm{NO}_{2}\right), 1320,1130\left(\mathrm{SO}_{2}\right) \mathrm{cm}^{-1}$; Anal. Calcd. for $\mathrm{C}_{24} \mathrm{H}_{34} \mathrm{ClNO}_{4} \mathrm{~S}_{2}$ : C 57.66, H 6.81, N 2.80; found C 57.73, 57.74, H 6.88, 6.91, N 2.87, 2.88\%.

General procedure for synthesis of 2-(1'-azido-1'-aryl)methylene-3-methyl-4-nitro-2,5dihydrothiophene- 1,1-dioxides $(10,11)$

Sodium azide $(2.3 \mathrm{mmol})$ was added to a solution of 1 or $\mathbf{2}(1.3 \mathrm{mmol})$ in glacial acetic acid (5 $\mathrm{mL}$ ). The reaction mixture was stirred for $1 \mathrm{~h}$, then precipitated 10, or 11 was filtered off, washed with ether, and dried in air.

2-(1'-Azido-1'-phenyl)methylene-3-methyl-4-nitro-2,5-dihydrothiophene-1,1-dioxide (10). Isolated as the Z,E-isomer; 49\%; mp $162-165^{\circ} \mathrm{C}$ (from acetic acid); ${ }^{1} \mathrm{H} \mathrm{NMR} \delta\left(\mathrm{CDCl}_{3}\right) 2.02\left(3 \mathrm{H}, \mathrm{s}, \mathrm{CH}_{3}\right) ; 4.52\left(2 \mathrm{H}, \mathrm{s}, \mathrm{CH}_{2}\right)$; $7.40(2 \mathrm{H}, \mathrm{dd}, \mathrm{J}=7.8 \mathrm{~Hz}, \mathrm{~J}=8.5 \mathrm{~Hz}, \mathrm{Ph}), 7.78(1 \mathrm{H}, \mathrm{t}, \mathrm{J}=8.5 \mathrm{~Hz}, \mathrm{Ph}), 8.05$ (2H, d, J = 7.8 Hz, Ph); IR v $\left(\mathrm{CHCl}_{3}\right) 1635(\mathrm{C}=\mathrm{C}), 1520,13301170\left(=\mathrm{NO}_{2}\right), 1330,1130\left(\mathrm{SO}_{2}\right), 2130\left(\mathrm{~N}_{3}\right) \mathrm{cm}^{-1}$; Anal. Calcd. for $\mathrm{C}_{12} \mathrm{H}_{10} \mathrm{~N}_{4} \mathrm{O}_{4} \mathrm{~S}$ : C 47.06, H 3.27, N 18.30; found C 47.14, 47.14, H 3.51, 3.54, N 18.35, 18.30\%.

2-(1'-Azido-1'-p-chlorophenyl)methylene-3-methyl-4-nitro-2,5-dihydrothiophene- 1,1-dioxide (11). Isolated as the $Z, E$-isomer; $42 \%$; mp $185-187^{\circ} \mathrm{C}$ (from acetic acid); ${ }^{1} \mathrm{H} \mathrm{NMR} \delta\left(\mathrm{CDCl}_{3}\right) 2.00$ $\left(3 \mathrm{H}, \mathrm{s}, \mathrm{CH}_{3}\right) ; 4.50\left(2 \mathrm{H}, \mathrm{s}, \mathrm{CH}_{2}\right) ; 7.65(2 \mathrm{H}, \mathrm{d}, \mathrm{J}=8.5 \mathrm{~Hz}, \mathrm{Ar}), 7.95(2 \mathrm{H}, \mathrm{d}, \mathrm{J}=8.5 \mathrm{~Hz}, \mathrm{Ar})$; IR $v$

$\left(\mathrm{CHCl}_{3}\right) 1630(\mathrm{C}=\mathrm{C}), 1520,1330\left(=\mathrm{NO}_{2}\right), 1330,1130\left(\mathrm{SO}_{2}\right), 2130\left(\mathrm{~N}_{3}\right) \mathrm{cm}^{-1}$; Anal. Calcd. for $\mathrm{C}_{12} \mathrm{H}_{9} \mathrm{ClN}_{4} \mathrm{O}_{4} \mathrm{~S}$ : C 42.39; H 2.64; N 16.45; found C 42.72, 42.70, H 2.79, 2.80, N 16.01, 16.03\%.

\section{References}

1. Lipina E.S.; Perekalin V. V. Acta Phys. et Chem. 1973, 19, 125.

2. Efremova I.E.; Bortnikov S.V.; Berestovitskaya V.M. Zh. Obsch. Khim. 2001, 71, 1047. 
3. Berestovitskaya V.M.; Efremova I.E.; Bortnikov S.V.; Litvinov I.A.; Kataeva O.N. Zh. Obsch. Khim. 2002, 72, 2035.

4. Mulliken R.S. J. Am. Chem. Soc. 1952, 74, 811.

5. Hidaway A.M.; Nassa A.M. G.; Issa R.M. Acta Chim. Acad. Sci. Hung. 1977, 92, 263.

6. Berestovitskaya V.M.; Efremova I.E.; Khlytin A.L.; Berkova G.A.; Pozdnyakov V.P.; Gamazin D.A. Zh. Org. Khim. 1996, 32, 152.

7. Efremova I.E.; Berestovitskaya V.M.; Lapshina L.V.; Felgendler A.V.; Nepomnyaschaya N.B. Zh. Org. Khim. 1998, 34, 1117.

8. Vassilieva M.V.; Berestovitskaya V.M.; Berkova G.A.; Pozdnyakov V.P. Zh. Org. Khim. 1986, 22, 428.

9. Energies of Chemical Bonds Break. Ionization Potentials and Electron Affinity, Kondratiev V.N.; Ed. Nauka: Moscow, 1974, p 351.

10. Heilbron I.; Bunbury H.M., Eds., Dictionary of Organic Compounds; Inostrannaya Literatura: Moscow, 1949, Vol. 1, 1024.

11. Hoggarth E., Sexton W.A. J. Chem. Soc. 1947, 815.

12. Westlake H.E., Dougherty G. J. Am. Chem. Soc. 1942, 64, 149. 